\title{
Devidayal's sons: \\ Satish and Ranjit Dhawan and the fellowship of flight
}

\author{
Jyotsna Dhawan $* \dagger$ \\ Centre for Cellular and Molecular Biology, Hyderabad 500 007, India
}

\section{A river and its banks}

FROM its source in underground springs near Manasarovar, the Indus courses north-west, and gathering up the Zanskar, plunges southward past the Karakoram range, accepting the waters of the Kabul and Kurram rivers on its western bank to sustain the city of Islamabad. Further south, meeting its five renowned eastern tributaries that give succor to Srinagar and Amritsar, Lahore and Multan, the ancient river flows through Punjab and Sindh to meet the Arabian Sea near Karachi. Every year, the Indus pours more water into the oceans than the equivalent of two Nile Rivers and three times the combined flow of the Tigris-Euphrates. Sometimes, at its mouth, the Indus waters experience a bore, where the leading edge of the incoming estuarine tide forms a wave that travels upstream. Historians speculate that the fleet of Alexander was obliterated in such an unexpected flow-reversing tidal bore.

\section{Dera Ismail Khan and pre-Independence Punjab}

Devidayal Dhawan was born in Dera Ismail Khan in 1890, the third child of Paira Ram Dhawan. Now part of the Khyber-Pakhtunkhwa province in Pakistan, Dera Ismail Khan was fleetingly assigned to the Northwest Frontier Province of British times, the very name conjuring a wild and uncharted territory, but in fact home to an ancient habitation, with pre-Harappan settlements close by, and situated on the bustling medieval MultanKandahar trade route, when caravans of citrus fruit and lacquered woodwork passed through. D. I. Khan, as its natives called it, is sandwiched between the gleaming Indus and the red mountains of the Khaisore Range, known as Ratta Koh. Long after most of them had moved to other towns on the Indus tributaries - Lahore on the Ravi, Amritsar on the Beas or Srinagar on the Jhelum, to pursue careers as lawyers, businessmen or army officers,

\footnotetext{
*This piece is dedicated to Lakshmi Khosla Dhawan, Nalini Nirodi Dhawan and Patricia Gregory Dhawan. It was written as a meditation on my father's life and times, and the influences that made him who he was. It is not meant as a history in any conventional sense. For readers who may be interested, a companion piece entitled 'Satish - chance and friendship in the arc of a life' has appeared in Bhavana Mathematics Magazine, July 2020.

†e-mail: jdhawan@ccmb.res.in
}

CURRENT SCIENCE, VOL. 119, NO. 9, 10 NOVEMBER 2020 the Dhawans retained links with their hometown, and spoke the Derawali dialect when together. A favourite anecdote of those days was of a disreputable ancestor, who professed to sell carrots from a handcart, but was in reality a minor conman. When a gullible target was found, he would apparently send word to his accomplices in the following code - 'fresh fruit ready, come soon'.

Devidayal's calling took him to Lahore to qualify for the bar. In 1915, he married Lakshmi Khosla, whose father Dhuni Chand Khosla, the chief medical officer of Kashmir had gained a reputation for his work during serial plague outbreaks of the 1900s. Unlike the first high courts in Bombay, Madras and Calcutta, the Lahore High Court had been established only in 1911 (along with those at Patna and Rangoon). With over 10 years of experience as a barrister, Devidayal was appointed as a judge and the couple moved many times, to towns and cities across pre-Independence Punjab. Their first two children Vimla and Satish were born in Srinagar, at Lakshmi's parental home, but with frequent changes of postings, the last three were born in Multan (Primla), Amritsar (Shukla) and Ludhiana (Ranjit).

\section{August 1947}

For several days, Devidayal's friends and colleagues in the Lahore High Court had tried to convince him that he

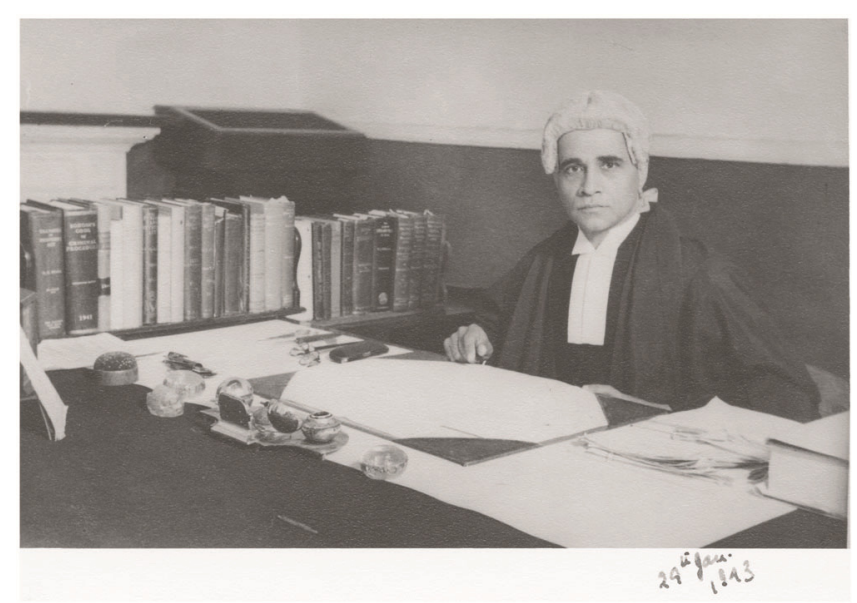

Justice Devidayal Dhawan, Lahore High Court, 1943 (Dhawan family collection). 
must temporarily relocate to Ferozepur, till after the border between Pakistan and India had been declared. He was very reluctant - Lahore was his home. Here Lakshmi and he had built a life: his career as a respected judge, a house in the cosmopolitan centre of Lahore where his children had been raised, their friends and community, their whole life was here. Could one uproot an identity? Where else could you belong except in the place you refused to leave? ${ }^{1}$ But with partition looming, Lakshmi and Devidayal resigned themselves to a temporary move. In the weeks leading up to Independence, Primla had gone to Vimla and her husband at Ferozepur, which was expected to be well inside India, while Shukla and Jit were sent to relatives in Simla. Satish was in California at graduate school, having left on a Government scholarship in 1945. Lakshmi packed the bare minimum needed for a few days stay in their daughter's house. Later, after the arrogance of a line drawn by a British civil servant had left a continent in uproar, Devidayal contemplated that fateful decision. No one could imagine that a cartographic convenience would be deployed as a surgical device, and offered up as an appropriate mechanism for birthing two nations from a single people. In reality, the pretense of precision was ludicrous, and the wound ran deep and incurable, the fallout catastrophic and the patched resolution ever uneasy. Urvashi Butalia speaks of the unacknowledged trauma '...if India and Pakistan remember partition with honesty, they would have to admit that politicians agreed for the sake of power to what became a bloodbath. The human cost was so heavy - and it continues even today. It is also very useful for India and Pakistan to demonise each other.... It makes any dialogue on difficult issues impossible. This is because there is an unacknowledged history, which we do not talk about. This is another reason why there are no memorials, although some sporadic efforts are being made'2.

Sometime after their displacement, Devidayal's friends in the administrative services asked if there was anything that a convoy coming from Lahore could collect from his house in Jail Road. A trusted servant in Lahore loaded on to the truck two metal trunks supposed to contain valuables, and some carpets. Back in Delhi, the trunks were opened to reveal neatly folded linen stored away in mothballs for the summer. From these trunks, we held our only artifacts of the brothers' Lahore childhood: exquisite embroidery crafted by Primla, delicate silk runners and lacquer boxes brought by itinerant Chinese merchants, and a faded line on the grey-blue Persian carpet marking a long-ago river flood, not in Lahore but an even earlier time in Srinagar.

\section{A pilot flexes his wings}

Ranjit Dhawan was born in Ludhiana in 1931, when Devidayal was posted to the District Court. A few years later, Devidayal was made a judge of the Lahore High Court, and the family settled in a comfortable bungalow at No. 36, Jail Road, conveniently located for Devidayal's work and the children's education. Satish cycled to attend Government College on the upper reaches of Mall Road, but the girls could just walk down to Kinnaird College for Women at 93 Jail Road, and the young Jit would be dropped off at Aitcheson College, a bit further away.

A mechanically minded motor enthusiast from early on, Jit was allowed to manoeuvre Devidayal's Model T out of the garage every morning even at age 9. In 1944, when Satish went to Bangalore for his practical training at HAL, Jit was hopping with excitement, as the older brother would get to work with the beautiful flying machines that had held him in thrall. The eleven years between the brothers did not affect their shared obsession with aviation. While Satish was getting his hands dirty working on warplanes in Bangalore, back in Lahore, Jit pored over any books he could find, and followed the news of every aircraft - the covers of Popular Mechanics magazine from the 1940 s were often illustrated with colour pictures of the latest aircraft. The exploits of the British Spitfires and German Messerschmitts were relayed in newsreels at the local cinema. The Royal Indian Air Force, an auxiliary wing of the RAF was already airborne in 1932 and had settled deeply in young Jit's mind.
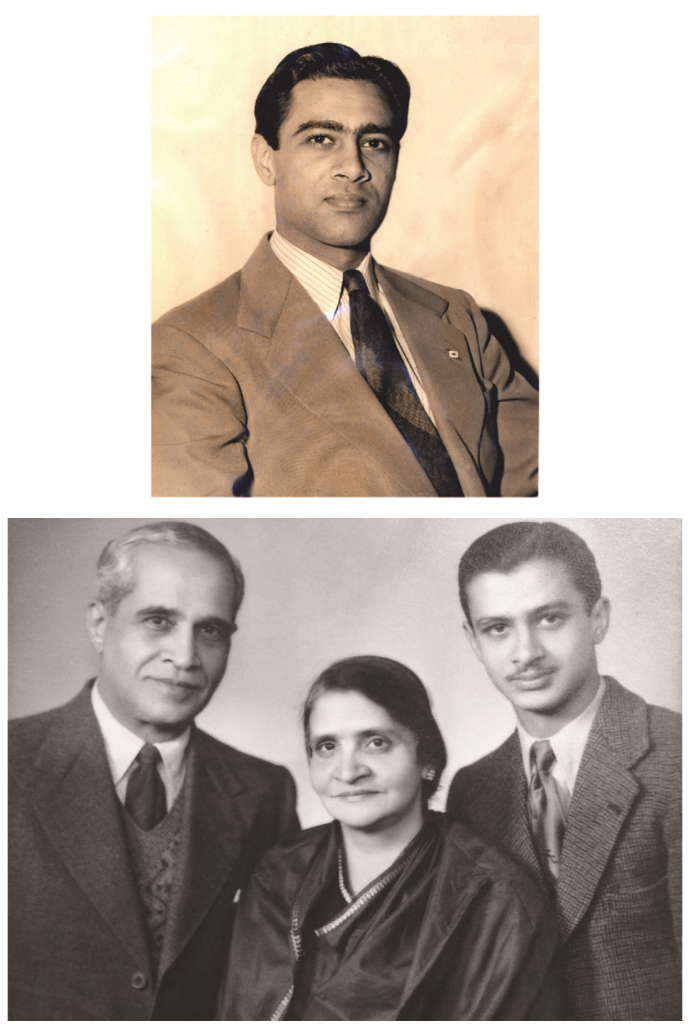

(Top) Satish Dhawan, c 1949, Pasadena (Dhawan family collection). (Bottom) Devidayal, Lakshmi and Ranjit Dhawan, c 1949, Simla (Dhawan family collection). 


\section{SATISH DHAWAN BIRTH CENTENARY}

While keen to immediately join the Indian Air Force the day he was eligible, Jit was persuaded by Devidayal to stem his impatience and complete his degree. Meanwhile, Satish saved up to indulge his brother's passion and enable him to obtain a private pilot's license in the US, as he himself had done. But with his year of waiting finally over, Jit joined the IAF in 1952, completing his training with the Flying Trophy.

\section{Monsoon cloudbank opens \\ Wings aloft \\ Loop de loop}

\section{The Indian Institute of Science, Bangalore 1957}

A long avenue of gul mohur trees lined the road from the Aero Dept to Bungalow No. 9. Now heading the department, Satish had moved on from his days of colourful Californian shirts and sporty little $\mathrm{MG}$, driven from his bachelor residence in a Quonset hut, a relic of WWII at the edge of the IISc campus (where the airfield later took shape). Arriving at IISc in 1951, Satish had with characteristic energy and relish, begun to put his Caltech training into action. Earlier, V. M. Ghatage, the aircraft designer responsible for the HT-2, the first aircraft to be designed and developed in India, had persuaded HAL to start a research programme at IISc. Satish had built on that legacy to add new wind tunnels. Roddam Narasimha (R.N.), Satish's first student, colleague and lifelong friend recalls how late-night experiments investigating the transition between turbulent and laminar flow, despite the primitive means of measurement and recording with manually operated devices, were cajoled into yielding quantitative data. R.N. joked that as Satish was not yet married, he would spend all his time in the lab.

Jawaharlal Vaid, an IISc graduate who had a distinguished career in industry, was a $\mathrm{PhD}$ student in Chemistry in the 1950s and recalls, 'I remember that Satish was

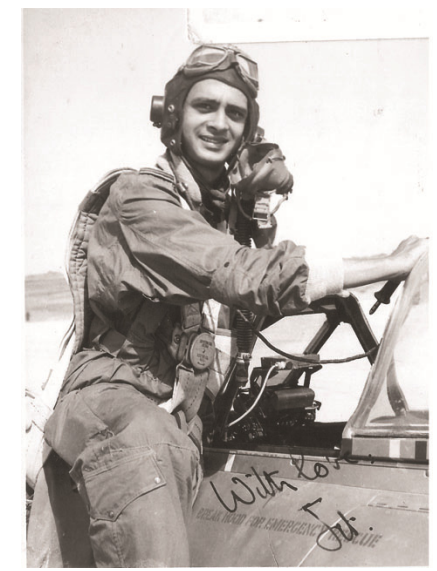

Jit Dhawan, IAF, Hyderabad 1953 (Courtesy: AVM Polly Singh). a dashing, tall and handsome young man, a good athlete, and every girl at IISc had her eyes on the bachelor - they used to spy on him. Then he married Nalini Nirodi, who was a beautiful and gracious lady. They were a lovely couple and she became the centre of attention for boys whenever she visited the Gymkhana! She was very friendly and everyone was enamored of her' ${ }^{3}$. Nalini had returned to her hometown Bangalore after a $\mathrm{PhD}$ in cytogenetics from Washington University, St Louis, and like Satish, had also resisted attempts by friends and family to pair her off with various 'possibles'. She met Satish in 1955, on the avenue outside the Aero Dept after a visit to her father B. S. Nirodi at the IISc Nursery. In that brief meeting, Satish and Nalini recognized in each other the kindred spirit neither had thought existed. Nalini was working at the Pusa Institute in Delhi at the time, but as soon as Devidayal and Lakshmi heard the news from their son, they brought Nalini to stay with them in Old Delhi. Nalini and Satish were married in Simla in July 1956, after Satish's return from a trip to China to attend a meeting of the World Federation of Scientific Workers.

So by 1957 , Satish was a householder ensconced in an airy first floor flat, made bright by his vivacious botanist wife and infant son. The long hours put into preparing his course notes and data sheets meant that his teaching skills had been honed by a few batches of students, his lab was buzzing with activity, and research questions in aerodynamics inspired by the problems of the fledgling aviation industry were central themes.

In his essay 'Test Flight' Gp. Capt. Shyam Hattangdi writes about an early encounter with Satish - 'We were two fifteen-year-olds with stars in our eyes. We had just

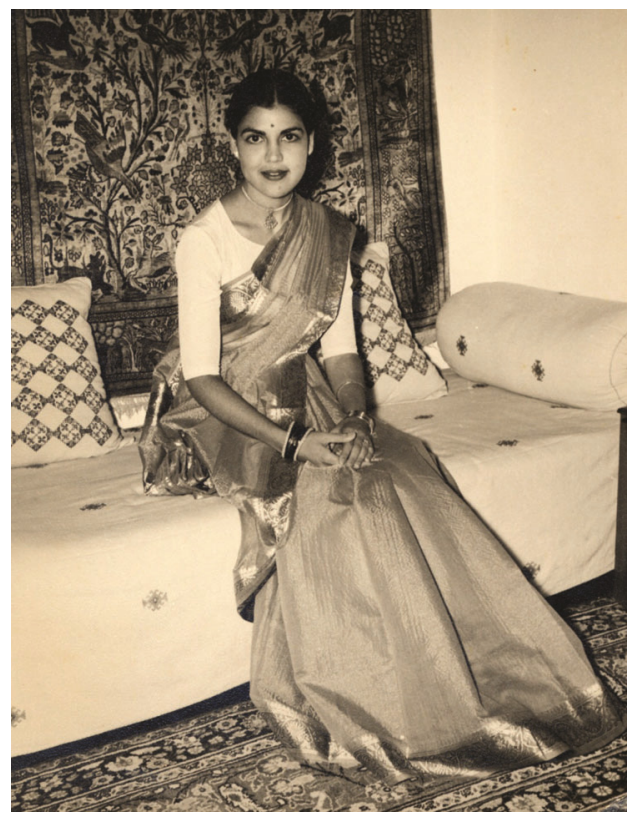

Nalini Nirodi, 1956, Simla, On her wedding day (Dhawan family collection). 
finished making our first powered model airplane. Building it hadn't been easy - no kits, model supplies, or superglue those days. The first task was to check out its gliding characteristics. So, holding my breath, I pointed the model into the wind and, with a silent prayer, launched it. Wham! With a sickening thud it nose-dived into the ground. "Aha. A model airplane." Till then unnoticed, the tall handsome man watching from behind us stepped forward: "Maybe I can help?" He picked up the model and balanced it on his index finger, adjusted the rubber bands around the wings and tail, folded a piece of paper and wedged it in... One more small adjustment and the next flight was an exhilarating, graceful glide.'

'But try as we may, the next step to powered flight was a disaster as the model was too heavy for the small engine. We would have to build another model from scratch. "Before you do that, there are a few things I think you should know." For the next 45 minutes, Satish went on to deftly draw and explain everything we needed to know about cambers and wingspans and aspect ratios, and static and dynamic balancing, and centers of gravity and pressure and how the various forces interact in an airplane. He made it so simple that we followed everything with total ease. That was over 50 years ago. I then flew many types of real planes, from light ones to supersonic jets to large passenger aircraft - my success attributable in no small measure to the crystal clear understanding of the basics given to me in that 45-minute session. I carried those drawings and notes with me for years...' As an IAF pilot, Shyam Hattangdi clocked the highest recorded flying hours on the Gnat Mk 1.

Roddam Narasimha's memories vividly describe those times, the prevailing ethos of the lab and the obsession with 'pretty little devices' to capture tiny changes in dynamic parameters of airflow ${ }^{4}$. Satish's guiding principle was to use precision-designed and purpose-built devices to make measurements that were critical to supporting aircraft design, or to understanding why elements of flight performance failed. These measurements had their own theoretical beauty as well, providing him the
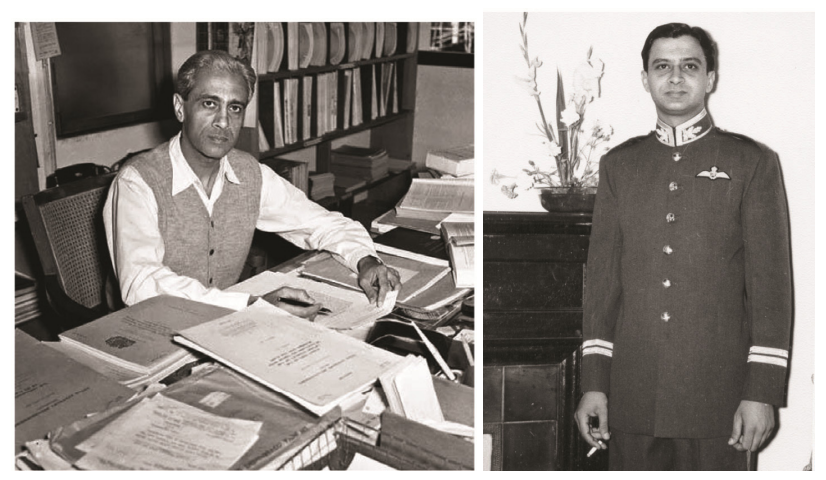

(Left) Satish, 1961, Aero Department Office (IISc collection). (Right) Jit, 1961, Ambala (Family collection). intellectual satisfaction of posing and resolving problems, but their execution by tailored engineering gave him joy. While there was practically no funding available for research, Satish delighted in devising home-made and locally sourced components for building these 'gizmos'. Sometimes, critical components missing from these assemblies came from friends in the US, and I remember hair-thin platinum wires arriving in envelopes with the Pasadena postmark. These were used by Narasimha to make 'hot wires' which were used to probe the dynamics of airflow. Imagine the audacity of conceiving and building a facility for testing elements of aircraft design, when neither funds nor for that matter aircraft, were yet available.

The glacial but methodical nature of research can never match the brief blinding clarity of purpose that must accompany setting out for war - yet both are required for success in battle - these activities define two ends of a spectrum in the theory and practice of flight.

\section{Squadron 'The Winged Arrows' Ambala, September 1965}

As in the peripatetic life of a judge, life in the Air Force involved continual relocation. Between ' 61 and ' 65 , Jit and his wife Patty moved five times between Ambala and Bareilly, their first home in Halwara being a Nissen hut (similar to the Quonset hut in which Satish found himself on IISc campus). From a childhood in Nagpur, the charismatic Patricia Gregory was working as a nurse in Calcutta when Jit met her. The story goes that when Jit drove Patty to Halwara after their wedding, she had mistaken the hut for the garage and gaily told Jit to park the car (a sporty little MG), only to be informed that the 'garage' was where they would live. Altogether, Patty set up 36 different homes over Jit's IAF career. It is no wonder that the resilient and resourceful wives of the armed forces are admired as a class apart.

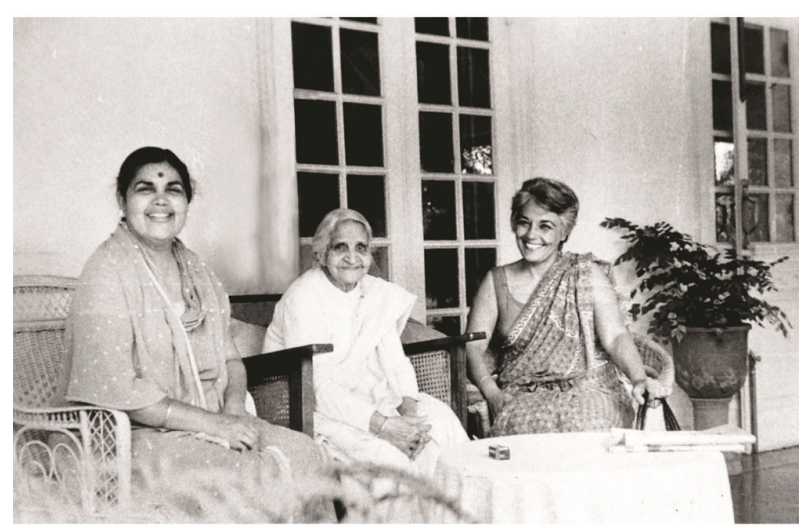

Nalini, Lakshmi and Patty. Bungalow No. 5, IISc, 1977 (Dhawan family collection).

CURRENT SCIENCE, VOL. 119, NO. 9, 10 NOVEMBER 2020 


\section{SATISH DHAWAN BIRTH CENTENARY}

Less than 20 years had passed since partition, but by mid-1965, there were already signs that military engagement was likely. By now a Squadron Leader, Jit was the flight commander of an operational squadron of Gnats in the 1965 war, whose missions included escorting bombers on raids and providing cover for ground troops. In Jit's own words: 'The Gnat was a difficult airplane in one sense. To fly ... accurately and level. More so, closer to the ground. Very sensitive. Fore and aft very sensitive. You could easily get into an oscillatory cycle of control, which does not dampen. ....all of sudden you could get into pilot-induced oscillations. And longitudinal control at that time was also a problem - there was something called a Hobson unit. A marvel of engineering skill, but to expect that finesse and fine tuning of control by mechanical means is disastrous. It was an ideal aeroplane to have fly-by-wire ${ }^{5}$, but a little before its time ${ }^{6}$.

The naming of fighter aircraft seems a quixotic affair some are named for explicitly threatening effect (Sabre, Thunderbolt), while others reveal metaphoric strengths (Mirage, Spitfire). The Gnat was a fighter whose name suited it perfectly - a tiny, light, speedy, pesky plane that was highly manoeuvreable in air-to-air engagement. The Folland Gnat (and its precursor the Midge) had been designed by WEW Petter, an Englishman, bucking the trend for larger, more complex and expensive fighters - the Gnat was his most famous design. As its production costs were favourable for a developing country like India, the Gnat was licensed for production by HAL in the late 50's, and this little fighter proved its capabilities, both in 1965 and 1971.

On the Gnat's 50th anniversary in 2008, Air Marshal P. K. (Babi) Dey who tested the early versions as a 24year old, remembered his encounter with the world's first lightweight fighter: 'I had seen the Gnat for the first time during the Farnborough Air Show in 1957 where the late Group Capt. Suranjan Das thrilled spectators from all

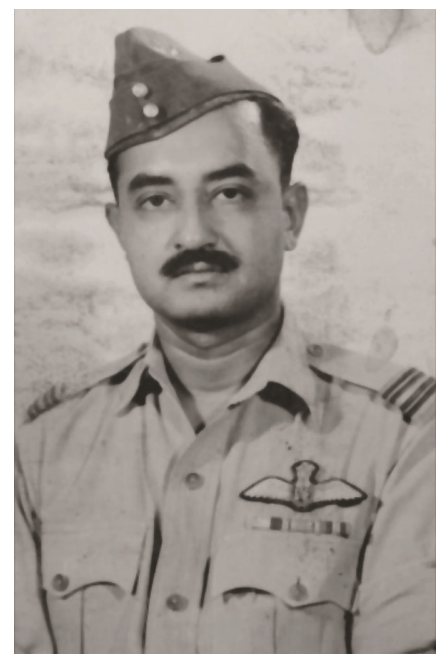

Gp. Capt. Suranjan Das, c. 1950 (Courtesy: Bharat Rakshak). over the world with his brilliant low level aerobatic display.... Prototype testing carries with it many sudden and unexpected pitfalls. And the Gnat was high spirited and moody and could never be taken for granted. ${ }^{7}$

\section{Fighter pilots - Artists in four dimensions}

In 2001, Jagan Pillarisetti, researching the IAF for his book on the 1965 war had interviewed $\mathrm{Jit}^{8}$. For me, just reading the transcript from the interview brought my uncle alive, his description of flying the Gnat in battle vivid, visceral and honest. 'You have to imagine doing maneuvers in combat which are really in four dimensions. You have to start a maneuver, anticipate where the other fellow has to be and 15 seconds later, he will be there and you will have to be there to position yourself. Your foresight and insight help you to maneuver into position. And at that same time, there is stress on you. Some guys say, I am not afraid, that's a bloody lie. You are afraid you will die, you are guarding your tail at the same time... In a very hostile and strenuous environment you have to be thinking precisely, in all these dimensions. You have to get better at your aim. And chances too. Suddenly he comes in front of you and you got your guns going. Not always that you can bait an enemy, unlike what happened in WW2, when it was a slower combat. Here in the Gnat, my God the bloody distance and the height maneuvering you could do was phenomenal. And in a dog-fight you are in a point of judder, and turn and heat - there he is, there, and you are going round and round to the point of judder, and all that you do is losing height. The first guy who breaks away is going to get shot. So this way you carry on, the guy who is lower, hits the ground earlier than you do. So there is an element of finality when you get into a dog-fight. There are methods of getting into it and out of it. Aircraft has to have good power, have combat flaps, combat maneuvering devices. The Gnat by itself was versatile (enough) to be able to do something. And ' 65 was full of fun. There was lot of confusion and fun.'

Wg Cdr Bharat Singh and Flt Lt A. K. Mazumdar of the Winged Arrows were awarded the Vir Chakra medal for their attack on F86 Sabres. Jit's Vayu Sena medal citation reads 'Thanks to his leadership and planning, the Gnats were able to give a good account of themselves against Pakistani aircraft of superior performance" ${ }^{\text {. }}$

\section{San Francisco 1991}

I waited at the gate as the flight touched down. In the years before commercial airliners had been redeployed as weapons of mass destruction, a visitor could walk all the way up to the arrival gate. Searching the disembarking passengers for my uncle, I located him - his walk only slightly less jaunty than I remembered, still springing 
with the vitality of the Air Force man. Now retired from the IAF and visiting America on business for a manufacturer of aircraft engines, Jit was still as excited as a boy to watch the great jets land. Neither the decades of flying fighter jets, nor the past 24 hours of travel had dulled for him the thrill of this routine enactment - with clarity and insight not available to the non-pilot, he detailed and marvelled at the skill of the air traffic controller in lining up the flights on the parallel sea-jutting runways, dispatching them serially into the wind with perfect timing, total safety. I missed all the hours with my father.

\section{The linked history of HAL, HF-24 and IISc Aeronautics Department}

Today, IISc Aero Department has the largest number of graduate students of any department on that buzzing campus, projects ranging from drones with hundreds of academic and societal applications to testing elements of supersonic aircraft and space applications, vibrant interactions with industry and computational facilities to be envied. In the late ' $50 \mathrm{~s}$, the government granted the princely sum of Rs 16 lakh for building advanced experimental facilities at IISc, and a range of high-speed, transsonic and supersonic wind tunnels were part of the new projects at Aero. By 1957, the wind tunnels developed by Satish and colleagues were already tackling problems inspired by issues facing the indigenous design of aircraft at HAL.

In 1954, Nehru had invited the German aircraft designer Kurt Waldemar Tank to HAL to spearhead the creation of an Indian fighter aircraft. Tank was a designer of extraordinary skill who had developed the Focke Wulf FW-190, arguably the most successful warplane of WWII. Although eclipsed by the Messerschmitt Bf109 for speed and manoeuvrability, the FW-190 was considered the most dependable fighter in the Luftwaffe and had made such decisive differences in battle that it was produced more than any aircraft in history (more than 20,000 planes in 1944), matched only by the Spitfire. The FW-190 is also credited with advancing aircraft technology with its innovative design. Leaving postwar Germany, like many of his countrymen, Tank had found refuge in Argentina. Panditji invited Tank to lead the design project, but the funding approval was slow, so Tank first spent time at the Madras Institute of Technology, then moved in 1956 to HAL in Bangalore. In one of the many convergences that characterize the history of Indian aerospace, one of Tank's students in Madras was A. P. J. Abdul Kalam. At HAL, with a German and Indian design team, Tank had a prototype of the HF-24 Marut ready by 1961.

Before heading to Caltech in 1945, Satish had spent his engineering degree practical training years at HAL, gaining a valuable first-hand understanding of Allied war- planes flown in from the Pacific Theatre to be repaired in Bangalore. In those student days, his powerful old Ariel motorcycle (bought second- or eleventh-hand) allowed him to outwit the packs of jackals that roamed the old Domlur road on the way to HAL. Now at IISc, Satish began working on problems that had implications for the HF-24 design, from late ' 57 onwards. Rao Valluri, Director of NAL and fellow Caltech graduate remembers 'Satish was instrumental in cleaning up the flow in the open circuit wind tunnel at IISc, and... generating the low speed aerodynamic data in it for the development of the HF-24 at HAL' ${ }^{10}$.

Eventually inducted into the IAF in 1967, the HF-24 could never sustain its supersonic dream due to its underpowered Orpheus engines, but it did deliver an excellent performance as a dependable fighter in the 1971 war. The Marutfans website contains many spirited reminiscences of IAF pilots who flew this plane, the first Asian fighter. In particular, the memoirs of the first HAL chief test pilot Gp. Capt. Kapil Bhargava sparkle with his love of the machine, his knowledge of the needs of a fighter pilot under pressure, and the back-and-forth of designer and pilot $^{11}$.

\section{Test pilots - the canaries in the aerial coal-mine}

In the ' 60 's, driving from IISc to HAL airport meant a long and winding journey past the Bangalore Palace and Cantonment Railway Station through Murphy Town, swinging past the Madras Sappers Regimental HQ at U1soor Lake (home of the famous 'Thambis' who invented the Bangalore Torpedo that was used to breach German defenses on the beaches of Normandy), and finally a long stretch down the Old Madras Road, with a variety of contortions via Domlur required to get to the HAL Airport Road. Today, while traffic density has increased to keep the journey just as long, the cross connection between the Old Madras Road and the HAL airport is easily accomplished via Suranjan Das Road. Gp. Capt. Suranjan Das 'Dasu' was the epitome of the test pilot: brave, debonair, and highly skilled. Trained at the famed Empire Test Pilot School in England, he had joined the Royal Indian Air Force in 1943, and was commanding officer at Ambala and Kanpur in the late '50s. When the HF-24 was to be tested in 1961, Dasu was the obvious choice. The citation of his AVSM awarded in 1962 reads 'Wg. Cdr. Das who has over 1,000 hours of test flying on nearly 35 different types of prototype and production aircraft has brought to bear his vast experience and knowledge in ensuring the success of the inaugural flight of HF-24. In undertaking the first successful test flight, Wg. Cdr. Das has rendered distinguished service of most exceptional order to aviation in India, ${ }^{12}$.

Commercial air travel is the safest mode of transportation by a huge margin, due in part to stringent tests 
carried out by hundreds of engineers over years. But what does it take to make an aircraft safe for flight in combat, when millisecond precision and responsiveness is the difference between life and death? Again, years of research and design tests, of all components individually, models, integration, avionics, repeated iterations of how disparate elements function together, 'boring' protocols, all must combine to underpin the flight, yielding the thrust and lift of the gravity-defying machine.

But in the end, it is the test pilot who actually puts his life on the line. With 1000 s of flying hours on a wide variety of aircraft to his credit, and hundreds of hours on successive versions of the HF-24, each test flight still carries unknown risks. Suranjan Das died on 9 January 1970 testing the new model of the HF-24 Marut, which crashed due to engine failure soon after take-off from HAL airport. He gave his life to make the HF-24 succeed as an aircraft. Suranjan Das was the son of Sudhi Ranjan Das, 5th Chief Justice of India who was born in Telirbagh near Dhaka. For the IAF fighter pilots of the 1971 war, their confidence in their crafts in the liberation of Bangladesh rested in part on the sacrifice made by Suranjan, a son of that soil.

\section{Squadron 'The Desert Tigers' Uttarlai, December 1971}

220 squadron had been moved to Uttarlai from Jodhpur in September of 1971, with the likelihood of war rising. In Jit's own words - 'I had a unique tenure of command of 220 (Squadron), the HF-24, because I founded the squadron from another number plate. It was (originally) a Vampire squadron. In '69 I took over. And I and Cpl. Chand, borrowed paper, borrowed a typewriter, (Air Marshal) Idris Latif gave me my rank to wear, and it started off from scratch literally... I ferried the first aeroplane from Bangalore. BD857. And carried out a supersonic (dive). There was nothing, not a starter trolley there. So I literally formed the squadron... I had a capable flight commander. Mini Menon was there earlier from Hunters. Joe Bakshi was also from Hunters. Both of them VrCs (Vir Chakra) in their own right... So we trained the squadron, took it to war and at the end of it, consolidated and

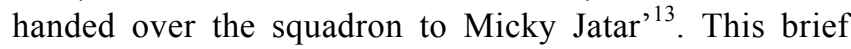
description skims over the enormous task of building a cohesive, well-trained unit of fighters from the ground up. Air Vice Marshal K. P. Sreekanth of 220 Sqn remembers Jit's abilities as a commanding officer in overcoming the challenges to achieving operational status at a Forward Base, in the face of shortages and logistical snarls when all supplies had to be transported from Jodhpur. All this, while keeping focused on consolidating the training for tactical flying and air-to-ground attack while operating from the Forward Base-but they were well prepared by September. Jit's reputation not just as a pilot, but also as a leader honed in the 1965 operations, was put to a greater test in 1971. Wg. Cdr. Keru Singh, then a young flying officer in the 220 recalls, 'Jit had a dynamic personality and his leadership style was unique - he was independent-minded and was very accessible to us youngsters... The HF-24 as a brand-new indigenous aircraft had many teething problems, just cajoling it into the air and keeping it flying was sometimes a challenge...'.

As commanding officer of the Desert Tigers, Sqn 220, Jit planned and executed 44 operational missions during the 13-day war, himself flying in 12 missions, successfully targeting airfields in Nawabshah, Hyderabad (Sindh), troop-trains at Mirpur Khas, and a beacon at Chor. The operations were conducted over the Indus floodplain, deep inside enemy territory. His cool head, honed aeronautical intuition and battle skills were critical not just for his own success and safety but also for that of his entire squadron, recognized with an AVSM at the 1972 Republic Day honors. While accepting the accolades of a grateful nation, he had also to face his 4-year-old daughter's accusing eyes when she realized that bombs released from the air kill people.

In the 1971 missions, Jit would have been flying over a landscape familiar not just from the military maps and deep preparation, but also from the emotional cartography of youth and family history. I found myself wondering whether the irony of his situation fleetingly occupied his mind. The answer came from his 2001 interview, when asked about flying in battle Jit said: 'A fighter pilot has got nothing, except his platform, that is his weapon, that is where he is sitting, that is exactly what it is, therefore you must fight on your own terms. In combat, sentiment does not prevail, no room for sentiment.' Irony, then, is only for the non-combatant with the luxury of looking back at a moment of extreme action and locating it in a context of their imagining.

The citation of the Ati Vishisht Seva Medal awarded to Jit for his contributions in 1971 reads 'During the December, 1971 war, Squadron Leader Dhawan was in command of a fighter-bomber squadron ... achievements (that) resulted in a major setback to the enemy. Ranjit Dhawan has displayed equal imagination and foresight. Under his command, the morale of his officers and men was always high.... Ranjit Dhawan has rendered distinguished service of an exceptional order.' The memoirs of Air Cmde JL 'Brother' Bhargava of 220 Sqn who was shot down on 5 December over Pakistan and spent over a year as a POW, mention Jit's leadership, as also Patty's calm and steadfast support to his wife when the news of Bhargava's capture reached Uttarlai ${ }^{14}$.

\section{April 1972 new responsibilities}

The untimely death of Vikram Sarabhai in December 1971 had landed new responsibilities on Satish's 


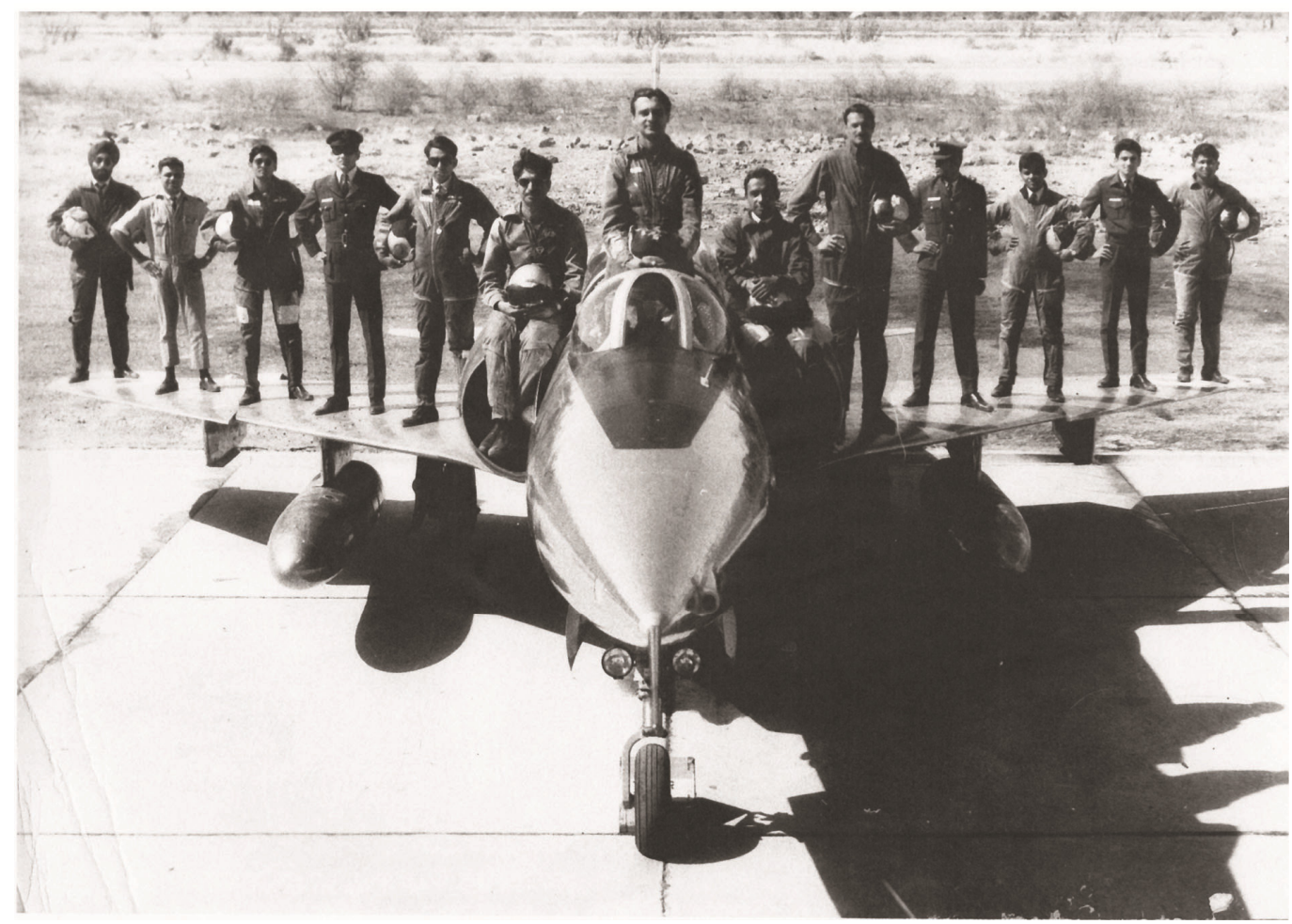

Jit with 220 Sqn pilots on HF-24 Marut 1971, Uttarlai, From left: Keru, B. R. Sharma, Shukla, ??, Sudhir Batra, R. P. Sharma, Boss Jit Dhawan, Brian, Dinky, S. K. Jatana, K. P. SreeKant, Kapoor, Sam Shekhar. (Courtesy: Wg Cdr Keru Singh.)

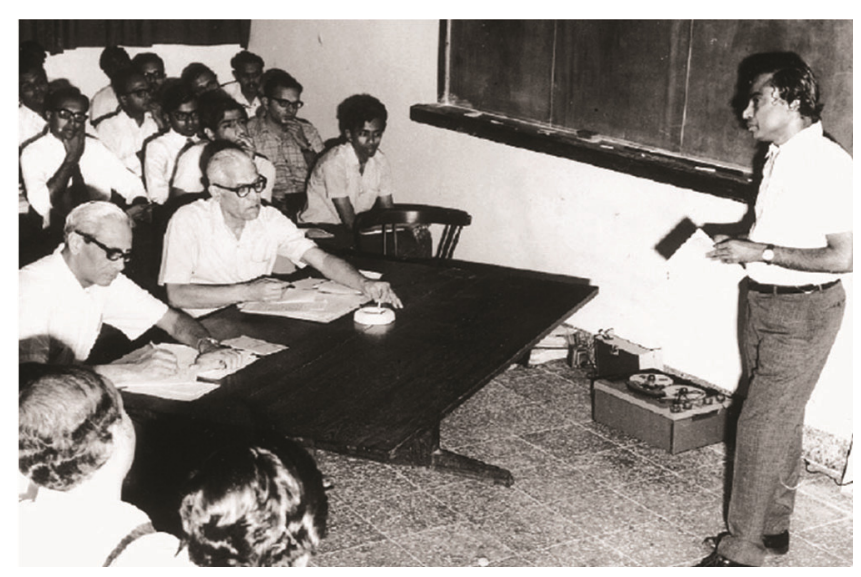

S. D. Brahm Prakash and others at SLV project review meeting, with A. P. J. Abdul Kalam presenting, 1979 (Courtesy: ISRO).

shoulders. In addition to serving as IISc's director, he was asked to head the Indian Space Research Organization, an organization pioneered and nurtured by Sarabhai. Then at an inflection point in its capabilities, ISRO's missions were already tuned towards building both satellites and launch vehicles, but neither had yet occurred. Satish's task was to ensure indigenous development and deployment of these programmes, essential as they were to India's path to self-reliance, in areas ranging from remote sensing and meteorology to telecommunications and defence. Both Sarabhai and Satish believed deeply that space technologies would help in solving real-world problems, and not only by a need to indulge humankind's existential curiosities. Both were pragmatic in their understanding of the implications of space science and nuclear energy for military purposes, but both were firmly committed to their peaceful use, leading to their active involvement with the Pugwash conferences on disarmament.

\section{January 1973 Abide with me}

It was early dusk and Rashtrapati Bhavan loomed to our left in the settling chill of the wintry twilight. Jit had led the IAF fly-past the previous year on Republic Day, a month after the end of the " 71 war. This year we were assembled at Vijay Chowk to witness the Beating Retreat, the ceremonial withdrawal of the troops from their yearly amassment at Delhi. Satish and other members of Jit's family were present. With the camels of the Bikaner Corps silhouetted against the sky on Raisina Hill, the bells rang out the hymn that the Mahatma cherished most, and which for the armed services is a universal symbol of honouring their heroes. Devidayal's family stood together in the deepening darkness, the highest clouds still faintly flushed with the last rays of sunlight. One had been a man of war, had gone to battle and been an agent of peace, one had fought to keep civilian control of potent engineering. 


\section{SATISH DHAWAN BIRTH CENTENARY}

Nations commit their young to acts of war on behalf of the idea of nationhood, they cast them in the roles of aggressor, defender, patriot or enemy; they reward those brief brutal moments with notions of valour and respect; the art of aggression has gone far beyond the brutality of trench warfare, sublimated with the beauty of technical precision. Not for the air warrior, the eviscerating horrors of hand-to-hand combat, but can the soul-weight of their actions ever leave them? In his even-handed descriptions of air-to-air combat in the 1971 war, Sameer Joshi scrupulously notes both Indian and Pakistani fighters, their skills, and their mental state, and in the very form of his reports clearly reveals the fundamental sameness of the adversaries ${ }^{15}$. As in Amitav Ghosh's writing, the borders are fluid, and the lines that connect are far stronger than the ones that separate ${ }^{16}$. Yet, these men find themselves on opposing sides of a battle. The term post-traumatic stress has become part of our everyday understanding of war, but the question of whether we can expect our defenders to integrate into the quotidian business of life after having given their all in battle is rarely honestly acknowledged. It seemed to me that the fighter pilots themselves may accept the attributes of glory and victory, and while their deepest allegiances may well be to other soldiers, they work for something larger than themselves. And yet, their inner life must somewhere bear the despair of having taken life, at however distant a displacement made possible by remote-controlled violence.

\section{Re-united in Bangalore}

In 1976, Jit took early retirement from the IAF - not for him the stifling progression to 'flying a desk'. Despite his success as a leader of his men in peace and in war, his first and deepest connection to the air force was in actual flight, the exhilaration that sustained the brotherhood of pilots for life. His new job in private industry involved a move to Bangalore, a deep reunion for the brothers. Having never had Satish's family nearby before, it was a wonderful new dimension to our lives to have not one, but two excited voices discussing all things aeronautical, and the similar but distinctive designs for making paper planes (with no less than 9 folds required just for fashioning the nose), launched with identical panache.

With both brothers settled in Bangalore after retirement, they could see each other more frequently than they had in the intervening half-century of working life. Often there would be an early morning visit in one house or the other. One such morning at Jit's house in Ashley Road, breakfast was done and we congregated in the living room. Jit had a new tape that he wanted Satish to hearhe played A. R. Rahman's Maa Tujhe Salaam, a passionate reworking of Vande Mataram. I can remember them sitting there transfixed, could feel the visceral response, a casting back to the freedom movement and their family life in Lahore, what the towering figures of Gandhi and Nehru inspired for them. Satish and Jit were patriots their own history derived from a broader notion of belonging to a shared heritage of a people. Not for them a narrow nationalism, but a sense of inter-belonging to a wider history, even if complex and conflicted. It seemed to me that the patriotic poem was inspired by something infinitely more ancient and elemental than the nation.

The 'Indus' no longer flows only through 'India', but the eternal river still springs from the same high mountains, passes by human habitation, and giving life, empties into the same sea, sometimes experiencing a tidal reversal. Thoughts still flow freely recognizing no boundaries. Every molecule in the universe originates in the stars and will return to interstellar space. Every fern spore and blue whale and Neanderthal has borrowed an assemblage of atoms forged in a distant stellar foundry for its instant in time. Today, as a pandemic sweeps the globe,

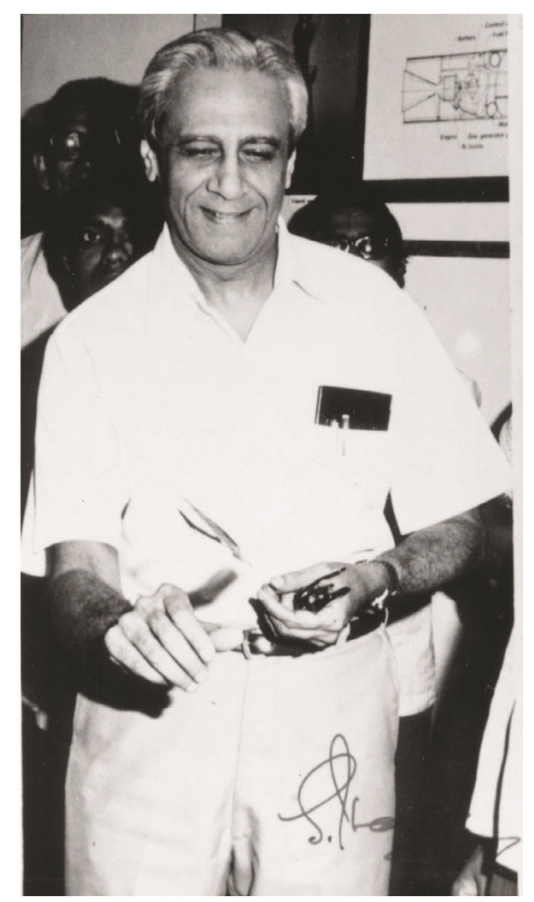

Satish flying a paper plane he just folded, IISc Aero Department 1981 (Courtesy: IISc).

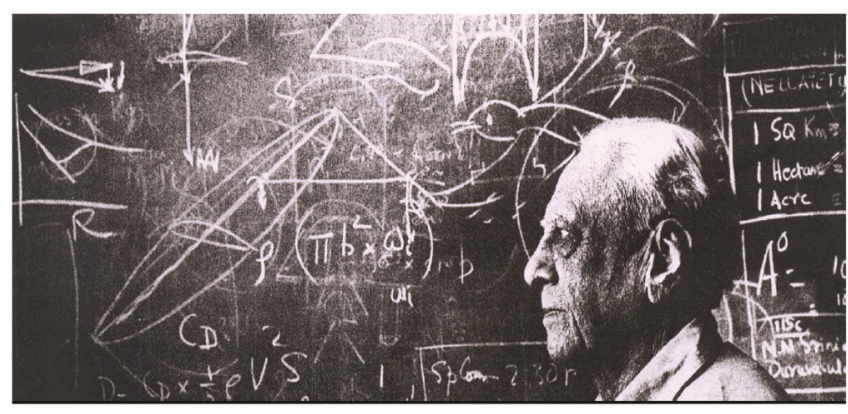

Satish Dhawan, Bangalore, c 2000, Bird Flight. 


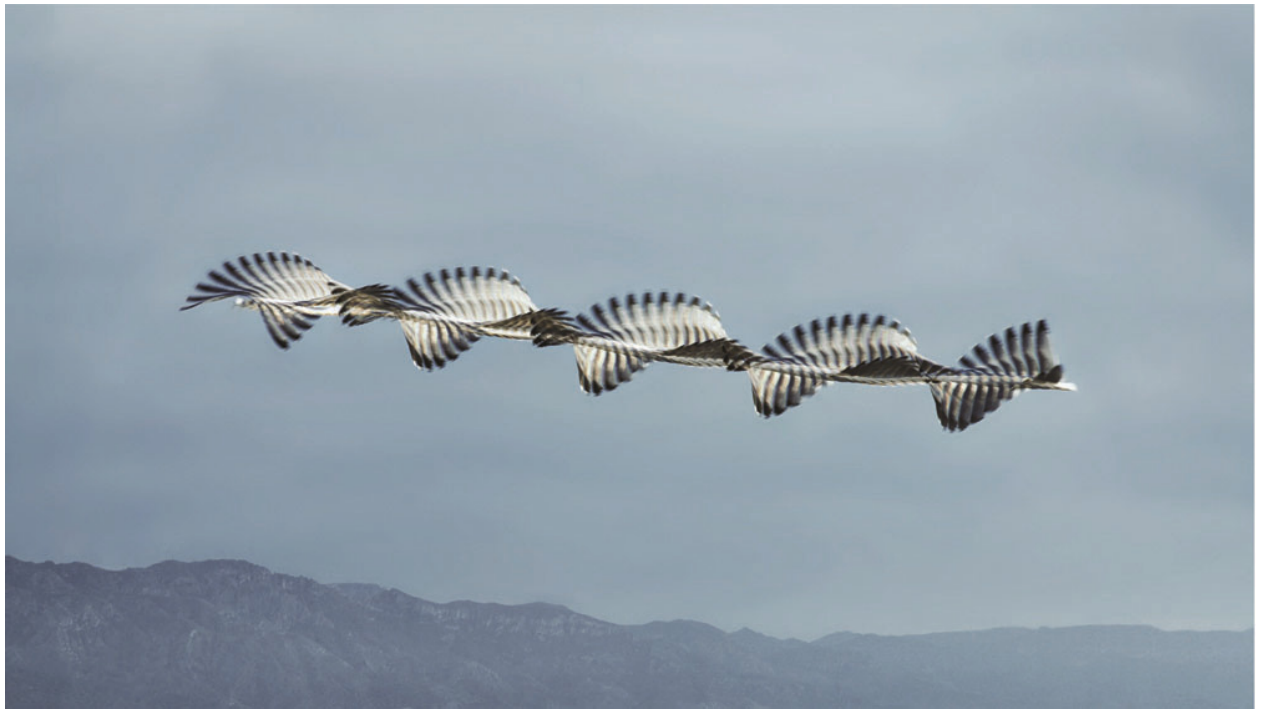

'Ornitography' Xavi Bou combines hundreds of photographs to capture in a single time frame, the shapes created by birds when flying, making visible the invisible; Copyright Xavi Bou, courtesy of the artist; http://xavibou.com/index.php/project/about-ornitographies/.

when we fear even the breath of nearby humans, I am reminded that even the virus holds the cosmos in its tightly wound genome. Satish and Jit have 'returned their borrowed stardust to the universe ${ }^{17}$. The two boys whose father grew up on the banks of an icy Himalayan flow in the shade of a red mountain, re-entered their cosmic cycle by mingling in the ferrous earth and warm rivers of the Deccan. But we are here now and we remember them for as long as we hold our stardust in trust.

\section{A bird in flight leaves no trace}

The Zen master Huangbo Xiyun wrote that to achieve enlightenment, one needed to let go of ones normal way of thinking ${ }^{18}$. In his last research work, Satish focused on bird flight, using the high-speed cameras and proximity to migratory birds offered by his frequent visits to Lake Pulicat near Sriharikota.

In the little book that grew out of this work, he thanked ISRO scientists for their help, and the birds for their participation $^{19}$. In his life, Satish studied elements of flight, and left a legacy that went beyond aeronautical research and space applications. As emblematic of all IAF pilots, Jit's legacy was the defense of freedoms that his brother held dear.

1. Amitav Ghosh in The Hungry Tide.

2. Urvashi Butalia in The Other Side of Silence: Voices from the Partition of India.

3. Excerpted with permission from IISc Connect; https://connect.iisc ac.in/2019/12/people-took-pride-in-their-work-and-in-the-institute/

4. Satish Dhawan obituary by Roddam Narasimha; http://www.iisc ernet.in/nias/sdhawan.htm, R.N. on S.D. in https://bhavana. org.in/roddam-narasimha/

5. Fly-by-wire refers to the electronic control interface for aircraft.

6. As told to Jagan Pillarisetti in August 2001
7. Air Marshal P. K. (Babi) Dey The Gnat And I; http://www.bharatrakshak.com/archives/gnat50/?p=382

8. Jagan Pillarisetti, The India-Pakistan War of 1965, Manohar Publishers, 2005.

9. http://www.bharat-rakshak.com/IAF/Database/Awards/awards. The Vayu Sena Medal awarded to Ranjit Dhawan was converted to a gallantry award as it was given for action during wartime.

10. S. R. Valluri in obituary of Satish Dhawan, NAL, 2002.

11. Gp Capt. K. Bhargava; https://marutfans.wordpress.com/2010/11/ 24/early-design-development-of-the-hf-24-gp-capt-kapil-bhargava$\operatorname{retd} /$

12. AVSM citation Gp Capt S. Das, Bharat Rakshak.

13. As told to Jagan Pillarisetti in 2001.

14. https://marutfans.wordpress.com/2010/11/08/the-pow-saga-part-iiiair-cmde-jl-bhargava-retd/

15. Sameer Joshi in The Print; https://theprint.in/author/sameer-joshi/

16. Amitav Ghosh, The Shadow Lines, 1988.

17. Maria Popova; https://www.brainpickings.org

18. https://wisdomexperience.org/product/bird-flight-leaves-no-trace/

19. Bird Flight, SD in Sadhana, 1991; republished by the National Book Trust of India.

20. http://xavibou.com/index.php/project/about-ornitographies/

ACKNOWLEDGEMENTS. I am grateful to many people for generously sharing their time, opinions and information. Jit's daughters Sonia and Mala Dhawan for their memories and permission to write about them, Jagan Pillarisetti for sharing his hour-long recording of an interview with Jit, and the benefits of his research into the history of the IAF in 1965 and 1971 wars, AVM Vikram 'Polly' Singh for photographs that allowed me to understand the camaraderie and connectedness of the IAF, Prof. Roddam Narasimha for discussions about SD \& HF-24 research at IISc, Gp. Capt. Shyam Hattangdi (retd) for permission to quote from his unpublished essay 'Test Flight', and with Wg. Cdr. Keru Singh (retd) and AVM K. P. Sreekanth (retd) for factchecking and insights into the IAF, $220 \mathrm{Sqn}$ and Jit's achievements, Vrinda Kumble for editing successive drafts, Ania Loomba, Amrita Dhawan, Vivek Dhawan, Imran Siddiqi, Rajan Sehgal and P. C. Balachandran Nair for helpful comments on the manuscript. The image capturing bird flight with high-speed overlays in a single frame is part of the 'Ornitographies' series by the Catalan artist Xavi Bou, who has generously permitted its reproduction here ${ }^{20}$.

doi: $10.18520 / \mathrm{cs} / \mathrm{v} 119 / \mathrm{i} 9 / 1479-1488$ 